\title{
Hydroxychloroquine and sulphasalazine alone and in combination in rheumatoid arthritis: a randomised double blind trial
}

Karen Lisbeth Faarvang, Charlotte Egsmose, Peter Kryger, Jan Pødenphant, Margrethe Ingeman-Nielsen, Troels Mørk Hansen

Department of Rheumatology, Kong Christian d X's Gigthospital, DK-6300 Graasten, Denmark K L Faarvang T M Hansen

Department of Rheumatology, Glostrup Hospital, University of Copenhagen, DK-2600 Glostrup, Denmark C Egsmore

Department of Rheumatology, Hvidovre Hospital, University of Copenhagen, DK-2650 Hvidovre, Denmark P Kryger

J Pødenphant

Department of

Radiology, Aalborg Hospital, DK-9100 Aalborg, Denmark $M$ Ingeman-Nielsen

Department of Rheumatology, Herlev Hospital, University of Copenhagen, DK-2730 Herlev, Denmark K L Faarvang $T M$ Hansen

Correspondence to: Dr Karen Lisbeth Faarvang, Department of Rheumatology 53Q1, Herlev Hospital, DK-2730 Herlev, Denmark.

Accepted for publication 28 June 1993

\begin{abstract}
Objectives-To compare the effects of hydroxychloroquine and sulphasalazine alone and in combination in rheumatoid arthritis.
\end{abstract}

Methods-A six month randomised, multicentre, double blind trial with three parallel groups was performed. Ninety one outpatients with active rheumatoid arthritis were included. Monthly assessments of erythrocyte sedimentation rate, morning stiffness, number of swollen joints, a pain score, and global assessments were carried out. Radiographs of hands and wrists were taken before and after the trial.

Results-Sixty two patients completed the study. The 29 withdrawals caused no evident bias, and there was no difference in side effects among the three groups. All variables improved significantly with time. Patients treated with a combination of hydroxychloroquine and sulphasalazine responded better and faster than those treated with hydroxychloroquine alone, but there was no statistically significant difference between the combination treatment and single drug treatment with sulphasalazine or between treatment with hydroxychloroquine and sulphasalazine given alone.

Conclusion-The present results do not support a recommendation to use a combination of hydroxychloroquine and sulphasalazine in the treatment of rheumatoid arthritis.

(Ann Rheum Dis 1993; 52: 711-715)

A combination of two or more disease modifying antirheumatic drugs might have advantages compared with treatment with a single drug in the management of rheumatoid arthritis (RA). Little is known about the biological effects of disease modifying antirheumatic drugs, but possible differences in their actions might be used in combination treatment through either additive or synergistic effects. Potential advantages could be increased effect, a faster onset of the effect, or a greater response rate.

The purpose of this investigation was to study whether a combination of sulphasalazine and hydroxychloroquine was superior to treatment with a single drug. The two drugs were chosen because of their low incidence of serious side effects. In addition, we aimed to determine whether previous treatment with gold salts or penicillamine affected the outcome. Finally, the selection of patients for the study from the total population of patients with RA at the three participating rheumatological clinics was recorded.

\section{Patients and methods}

PATIENTS

During the inclusion period 776 patients with RA were registered in the three participating departments. Ninety one of these met the criteria for inclusion in the trial. They all had RA defined according to the American Rheumatism Association 1958 criteria. ${ }^{1}$ The mean age was 61 years (range 18-82) and the male to female ratio was $35: 56$. The mean duration of RA was 6.3 years (range $0-37$ ) and $71 \%$ belonged to Steinbrocker's functional class I and $29 \%$ to class II. ${ }^{2}$ All the patients had active disease - that is, at least three swollen joints and at least two of the following three criteria: (a) a minimum of six tender joints; $(b)$ duration of morning stiffness of 45 minutes or longer; or $(c)$ an erythrocyte sedimentation rate (ESR) greater than $28 \mathrm{~mm} / \mathrm{h}$. Patients were excluded based on the criteria given in table 1 .

The patients were randomised using a table of random numbers of three parallel groups and a double blind technique was used. The study was performed in accordance with the Helsinki declaration II and was approved by the local ethical committees.

Table 1 No of patients excluded according to the criteria used in this study

Lack of disease activity

Functional class III or IV (Steinbrocker ${ }^{2}$ )

Age $<18$ years

Pregnant or lactating women

Previous treatment with HC or SASP, or both

Treatment with disease modifying antirheumatic

drugs within one month

Malignancies

Glucocorticosteroids within last six weeks

Refused participation

Allergic to the drugs in question, or eye disease

which contraindicates $\mathrm{HC}$

Each patient could be recorded with more than one exclusion criterion. The total number of excluded patients was 685 . $\mathrm{HC}=$ Hydroxychloroquine; $S A S P=$ sulphasalazine. 
TREATMENT

The patients were allocated to six months of treatment with (a) hydroxychloroquine 250 $\mathrm{mg} /$ day and placebo (resembling enteric coated sulphasalazine $2 \mathrm{~g} /$ day), (b) sulphasalazine 2 g/day (enteric coated tablets) and placebo (resembling hydroxychloroquine $250 \mathrm{mg} /$ day), or (c) hydroxychloroquine $250 \mathrm{mg} /$ day and sulphasalazine $2 \mathrm{~g} /$ day (enteric coated tablets). The patients were allowed to continue current treatment with non-steroidal anti-inflammatory drugs, paracetamol, and dextropropoxyphene during the study.

\section{INVESTIGATIONS}

Before onset, and once a month throughout the trial, disease activity was assessed by the same observer in each centre. Assessments consisted of a recording of the ESR, the duration of morning stiffness, number of swollen joints $(0-40)$, a pain score (none $=0$, mild $=1$, moderate $=2$, severe $=3$, very severe $=4$ ), and the global assessments of the patients and doctors (better $=1$, unchanged $=0$, worse $=-1$ with respect to the previous visit). Side effects were noted. Radiological examinations were performed blindly at the time of randomisation and six months later by the same radiologist. The following joints were evaluated for definite RA change (that is, juxtaarticular erosions with a diameter of at least one millimetre, or marked narrowing of the joint space combined with subluxation): the metacarpophalangeal and proximal interphalangeal joints; interphalangeal joint of the thumb, wrist (evaluated as one joint); metatarsophalangeal joints; and the interphalangeal joint of the first toe and the tarsus (evaluated as one joint). The number of joints with definite RA changes was counted and the two sets of images was compared for marked progression of the number or size of lesions. This method has been used previously and has been described in detail elsewhere. ${ }^{3}$ Routine laboratory tests were performed once a month and an ophthalmological examination was carried out every third month. Previous treatment with gold salts or penicillamine, or both, was recorded.

SAMPLE SIZE AND STATISTICAL METHODS

We wanted to be reasonably sure of finding significant differences in the trial if there was a difference of at least $25 \%$ between two treatments. For this reason we set $2 \alpha=5 \%$ and the power to $80 \%$. The standard deviation was estimated to be $30 \%$. Considering also the possibility of a dropout rate of up to $30 \%$ we estimated that each group should comprise 30-35 patients at randomisation.

The statistical evaluation of the results was carried out using a non-parametric model corresponding to one and two way ANOVA. ${ }^{3}$ The factors were treatment and time (repeated measures). In addition, parametric analyses were performed; only $p$ values $<0.05$ were regarded as statistically significant.

The primary analyses were based only on those patients who completed the stipulated trial time and supplied the required data. To delimit the potential for bias due to various reasons for withdrawal (table 3 ) we performed additional analyses in which missing data were input. These outside analyses were based on those completing a shorter trial time and used interpolation, extrapolation (carrying last value forwards), and regression models. These analyses all yielded principally the same conclusion with respect to the comparison between treatments.

Table 2 Median (25/75 centiles) (at baseline) values during six months of treatment with hydroxychloroquine (HC), sulphasalazine ( $S A S P)$, or a combination of the two $(H C+S A S P)$

\begin{tabular}{|c|c|c|c|c|c|c|c|}
\hline \multirow[t]{2}{*}{ Drug treatment } & \multicolumn{7}{|l|}{ Month } \\
\hline & 0 & 1 & 2 & 3 & 4 & 5 & 6 \\
\hline $\begin{array}{l}\operatorname{ESR}(\mathrm{mm} / \mathrm{h}) \\
\operatorname{HC}(n=23) \\
\operatorname{SASP}(n=17) \\
\operatorname{HC}+\operatorname{SASP}(n=22)\end{array}$ & $\begin{array}{l}48(30 / 80) \\
48(34 / 84) \\
53(32 / 67)\end{array}$ & $\begin{array}{l}42(21 / 73) \\
39(16 / 62) \\
41(17 / 52)\end{array}$ & $\begin{array}{l}44(17 / 76) \\
27(14 / 59) \\
24(9 / 51)\end{array}$ & $\begin{array}{l}37(17 / 84) \\
27(9 / 49) \\
19(7 / 32)^{\star}\end{array}$ & $\begin{array}{l}37(17 / 76) \\
28(10 / 36) \\
18(6 / 32)^{\star}\end{array}$ & $\begin{array}{l}31(10 / 63) \\
25(7 / 32) \\
16(7 / 25)\end{array}$ & $\begin{array}{l}33(10 / 60) \\
16(9 / 43) \\
16(9 / 33)\end{array}$ \\
\hline $\begin{array}{l}\text { Morning stiffness (min } \\
\text { HC }(n=23) \\
\text { SASP }(n=17) \\
\text { HC+SASP }(n=22)\end{array}$ & $\begin{array}{l}\text { tes) } \\
60(30 / 120) \\
60(30 / 120) \\
60(60 / 120)\end{array}$ & $\begin{array}{l}60(30 / 113) \\
45(26 / 90) \\
60(30 / 60)\end{array}$ & $\begin{array}{l}60(16 / 120) \\
30(26 / 68) \\
30(0 / 60)\end{array}$ & $\begin{array}{l}60(6 / 90) \\
30(0 / 41) \\
18(0 / 60)\end{array}$ & $\begin{array}{l}30(6 / 60) \\
15(4 / 60) \\
18(0 / 60)\end{array}$ & $\begin{array}{r}15(1 / 60) \\
15(0 / 38) \\
5(0 / 30)\end{array}$ & $\begin{array}{r}15(1 / 80) \\
15(4 / 38) \\
5(0 / 30)\end{array}$ \\
\hline $\begin{array}{l}\text { Number of swollen join } \\
\text { HC }(n=23) \\
\text { SASP }(n=17) \\
\text { HC+SASP }(n=22)\end{array}$ & $\begin{array}{l}\text { s }(0-40) \\
9(5 / 13) \\
8(5 / 13) \\
10(6 / 12)\end{array}$ & $\begin{array}{l}8(6 / 11) \\
8(7 / 12) \\
8(5 / 10)\end{array}$ & $\begin{array}{l}8(6 / 12) \\
6(4 / 8) \\
7(3 / 8)\end{array}$ & $\begin{array}{l}7(4 / 11) \\
5(4 / 8) \\
5(2 / 7)\end{array}$ & $\begin{array}{l}6(4 / 11) \\
5(2 / 8) \\
3(1 / 6)^{\star}\end{array}$ & $\begin{array}{l}5(3 / 7) \\
3(2 / 6) \\
4(2 / 6)\end{array}$ & $\begin{array}{l}5(2 / 7) \\
4(1 / 6) \\
2(1 / 3)^{\star}\end{array}$ \\
\hline $\begin{array}{l}\text { Joint pain }(0-4) \\
\text { HC }(n=23) \\
\text { SASP }(n=17) \\
\text { HC+SASP }(n=22)\end{array}$ & $\begin{array}{l}2(2 / 3) \\
2(2 / 3) \\
2(2 / 3)\end{array}$ & $\begin{array}{l}2(2 / 2) \\
2(2 / 2) \\
2(2 / 2)\end{array}$ & $\begin{array}{l}2(2 / 2) \\
2(1 / 2) \\
1(1 / 2)\end{array}$ & $\begin{array}{l}2(1 / 2) \\
1(1 / 2) \\
1(1 / 2)^{\star}\end{array}$ & $\begin{array}{l}2(1 / 2) \\
2(1 / 2) \\
1(1 / 2)\end{array}$ & $\begin{array}{l}1(1 / 2) \\
2(1 / 2) \\
1(0 / 2)\end{array}$ & $\begin{array}{l}1(1 / 2) \\
2(1 / 2) \\
1(1 / 2)\end{array}$ \\
\hline $\begin{array}{l}\text { Patients' global assessn } \\
\text { HC }(n=23) \\
\text { SASP }(n=17) \\
\text { HC+SASP }(n=22)\end{array}$ & nts (accumu & $\begin{array}{l}\text { d values of }-1 \\
0(-1 / 1) \\
0(0 / 1) \\
1(0 / 1)^{\star}\end{array}$ & $\begin{array}{l}+1) \dagger \\
0(-1 / 1) \\
1(1 / 2) \\
1(0 / 2)^{\star}\end{array}$ & $\begin{array}{l}0(-1 / 1) \\
2(1 / 2) \\
2(1 / 3)^{\star}\end{array}$ & $\begin{array}{l}0(-1 / 2) \\
2(1 / 3) \\
2(1 / 3)^{\star}\end{array}$ & $\begin{array}{l}1(0 / 3) \\
2(2 / 3) \\
3(2 / 4)^{\star}\end{array}$ & $\begin{array}{l}1(0 / 3) \\
2(1 / 3) \\
3(2 / 4)^{\star}\end{array}$ \\
\hline $\begin{array}{l}\text { Doctors' global assessn } \\
\text { HC }(n=23) \\
\text { SASP }(n=17) \\
\text { HC+SASP }(n=22)\end{array}$ & ts (accumu & $\begin{array}{l}\text { values of }- \\
0(-1 / 1) \\
0(0 / 1) \\
1(0 / 1)^{\star}\end{array}$ & $\begin{array}{l}+1) \dagger \\
0(-1 / 1) \\
1(0 / 1) \\
1(0 / 2)^{\star}\end{array}$ & $\begin{array}{l}0(0 / 1) \\
2(1 / 2) \\
2(1 / 3)^{\star}\end{array}$ & $\begin{array}{l}1(0 / 2) \\
2(1 / 3) \\
2(1 / 3)^{\star}\end{array}$ & $\begin{array}{l}1(0 / 3) \\
2(1 / 3) \\
3(2 / 3)^{\star}\end{array}$ & $\begin{array}{l}1(0 / 3) \\
2(1 / 3) \\
3(1 / 4)\end{array}$ \\
\hline
\end{tabular}

$\mathrm{p}$ (Time) $<0.01$ for all six variables.

${ }_{\mathrm{p}} \mathrm{p}$ (Treatment)<0.05 (combination treatment superior to hydroxychloroquine)

$t-1=$ Worse, $0=$ unchanged, $+1=$ better, in relation to the previous visit. 


\section{Results}

Thirty one patients were treated with hydroxychloroquine and placebo, 29 with sulphasalazine and placebo, and 31 with hydroxychloroquine and sulphasalazine. Sixty two patients completed the six months of treatment (23 hydroxychloroquine, 17 sulphasalazine, and 22 hydroxychloroquine and sulphasalazine). At inclusion there was no statistically significant difference between the three groups.

There was no significant difference between hydroxychloroquine and sulphasalazine treatment. Neither was there any significant difference between combination and single drug treatment with sulphasalazine. The combination treatment, but not the single drug treatment with sulphasalazine, was, however, significantly better than single drug treatment with hydroxychloroquine (ESR months 3 and 4 , number of swollen joints months 4 and 6 , joint pain month 3 , patients' global assessments months 1-6, and doctors' global assessments months 1-5) (table 2; figs 1-3).

Radiographs of the hands and wrists showed a slight progression of the lesions specific to RA in all groups after six months of treatment $(\mathrm{p}<0.01)$, but there was no statistically significant difference among the three groups. The patients receiving hydroxychloroquine showed a median increase in erosions in 0.6 joints, and the patients receiving sulphasalazine or combination treatment in 0.4 joints. Most of the patients showed no changes in lesions specific to RA during the trial and no patients showed a decrease in the number of lesions.

Of the 29 patients who withdrew from the trial (table 3 ), the main reasons were gastrointestinal side effects (four patients receiving sulphasalazine, six receiving hydroxychloroquine, and three receiving combination treatment) and hypersensitivity (three receiving sulphasalazine, one receiving hydroxychloroquine, and two receiving combination treatment). There was no significant difference between the three treatment groups and no serious side effects were recorded. No

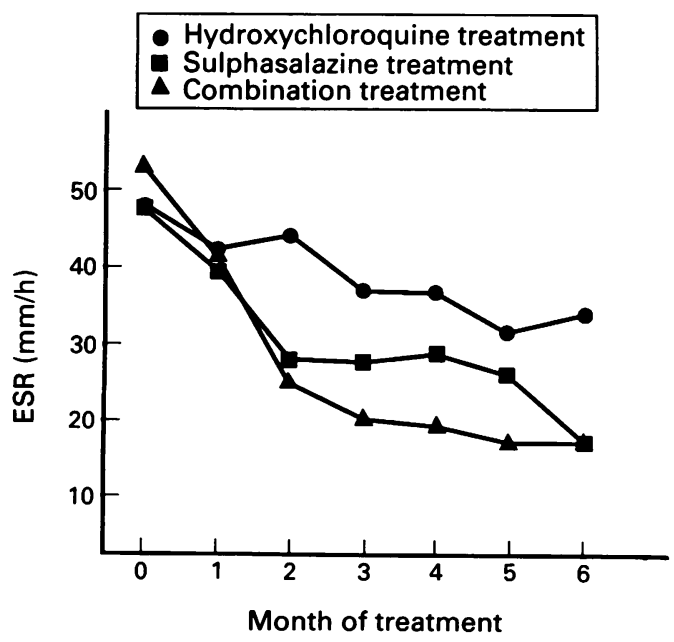

Figure 1 Effect of drug treatment on median erythrocyte sedimentation rate (ESR).

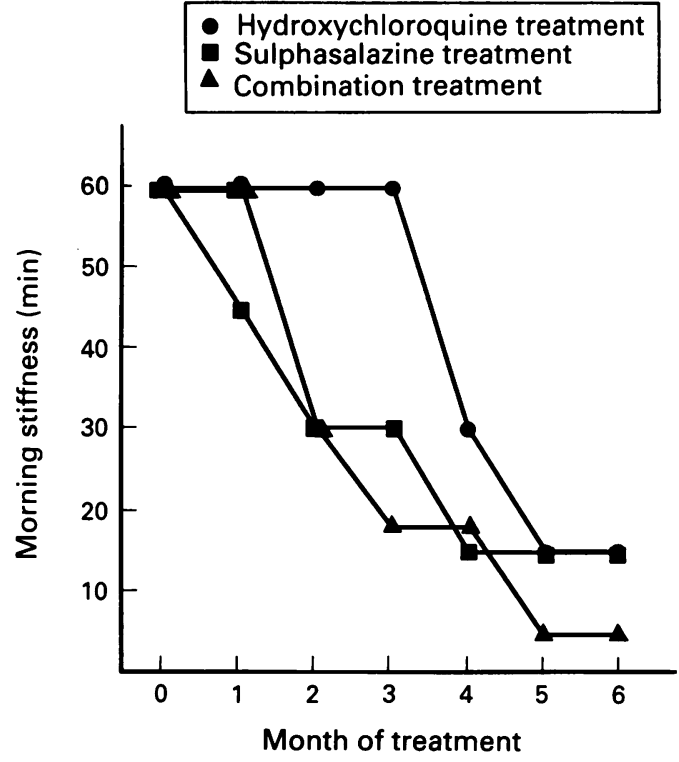

Figure 2 Effect of drug treatment on median length of morning stiffness.

ophthalmological side effects to hydroxychloroquine treatment were seen.

Thirty nine patients had previously been treated with gold salts and 36 patients with penicillamine. The disease was of longer duration in these patients (mean of 12 years compared with one year), but no statistically significant difference in response to any of the drug regimens was noted in these patients.

Seven hundred and seventy six patients with RA were initially registered but 685 were excluded (table 1 ). The main reasons were lack of disease activity ( 408 patients), either due to inactive disease or ongoing treatment with disease modifying drugs (328 patients) or glucocorticosteroids (158 patients). Each patient could be registered with more than one exclusion criterion.

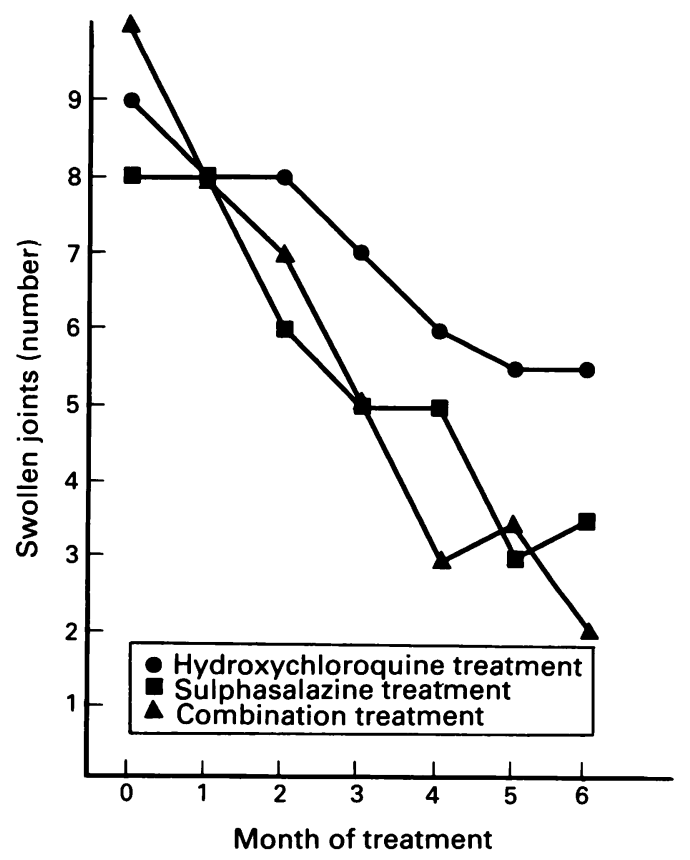

Figure 3 Effect of drug treatment on median number of swollen joints. 


\section{Discussion}

In a randomised double blind study of combination treatment with sodium aurothiomalate and penicillamine McKenna et $a \bar{l}$ found that significant clinical and biochemical improvements were seen within four weeks of combination treatment, whereas treatment with a single drug showed an effect after eight weeks; otherwise the efficacy appeared to be similar among the three groups. Scott et at found in a randomised double blind study a small advantage of combination treatment with sodium aurothiomalate and hydroxychloroquine compared with treatment with sodium aurothiomalate alone after one year of treatment. They tested 13 clinical laboratory, and radiological variables and favoured the combination treatment by $20-25 \%$, though only the $\mathrm{C}$ reactive protein and an overal disease activity index differed significantly. An analysis of the transitory interaction between the two groups was not performed. Two randomised studies of a combination of antimalarial drugs and penicillamine showed no beneficial effects of the combination treatment. ${ }^{78}$ Surprisingly, in one of the studies $^{7}$ the group receiving combination treatment did not fare as well as the group receiving penicillamine alone. Williams et a ${ }^{\rho}$ have compared auranofin, methotrexate, and the combination of the two in a double blind randomised trial. Except for fewer withdrawals because of a lack of response, the combination treatment did not show any advantage over treatment with a single drug.

In addition to these five randomised studies a number of open studies and case reports have been published. Most of these indicated that combination treatment was effective and potentially advantageous compared with treatment with a single disease modifying antirheumatic drug. ${ }^{10-14}$

The significant differences in this study between a combination treatment with hydroxychloroquine and sulphasalazine and treatment with a single drug (hydroxychloroquine) (table 2) may indicate a better and faster effect with the combination treatment. There was, however, no significant difference between combination treatment and treatment with sulphasalazine alone, so it is a question of whether the combination treatment with its higher cost and potential risk of more side effects is of any clinical importance. Most studies have shown more side effects with combination treatment..$^{59-11}$ In this study

Table 3 Reasons for withdrawal from the trial. Values are number of patients

\begin{tabular}{lcll}
\hline & \multicolumn{3}{l}{ Drug treatment } \\
\cline { 2 - 4 } & $S A S P$ & $H C$ & HC/SASP \\
\hline Gastrointestinal symptoms & 4 & 6 & 3 \\
Hypersensitivity & 3 & 1 & 2 \\
Adenocarcinoma coli & 1 & 0 & 0 \\
Non-compliance & 4 & 1 & 1 \\
Missing data & 0 & 1 & 2 \\
Total & 12 & 9 & 8 \\
\hline
\end{tabular}

${ }^{\star} \mathrm{HC}=$ Hydroxychloroquine, SASP=sulphasalazine, and $\mathrm{HC}$ $\mathrm{SASP}=$ hydroxychloroquine and sulphasalazine in combination. there were no indications of an increased risk by combining hydroxychloroquine and sulphasalazine (table 3 )

It is possible that an increase in the dose of hydroxychloroquine could have improved the effect of this treatment as well as that of combination treatment, but we chose a relatively small dose $(250 \mathrm{mg} /$ day $)$ to avoid ophthalmological side effects, which may be a risk, particularly in long term treatment. Lower doses of hydroxychloroquine were used in some studies. ${ }^{6-8}$ For hydroxychloroquine and sulphasalazine we chose fixed, not weight related, doses to make it possible to carry out a double blind trial.

Most studies have shown more side effects if combination treatment was used. ${ }^{6}{ }^{810-12}$ There was no indication of an increased risk by combining hydroxychloroquine and sulphasalazine in the present study.

Previous treatment with gold salts or penicillamine did not affect the response to treatment nor withdrawal profiles. At randomisation these patients had had RA for a much longer time than patients without treatment with these drugs (mean 12 years $v 1$ year). Previous studies have shown that the effect of disease modifying antirheumatic drugs is negatively correlated with the duration of RA, ${ }^{15}$ possibly owing to more irreversible changes in patients with longstanding RA. In this study this was counteracted by the exclusion of patients in functional groups III and IV.

There are several possibilities for bias in controlled trials. Firstly, we had a substantial attrition of patients before randomisation because only patients referred to the participating departments could be enrolled and of these many did not fulfil the inclusion criteria (table 1). This may exclude less complicated cases and perhaps patients who are better responders. Secondly, about $30 \%$ of the patients randomised did not complete all six months of treatment. The former is a bias only as far as the definition of our target population is concerned, whereas the latter is a real potential for bias in comparisons between treatments. Accordingly, we conducted several additional statistical analyses. Although the possibility of bias remains-primarily because the reasons for withdrawal may differ even though numbers were comparable-we found no evidence of this.

The previously randomised studies of combination treatments differ in design and analysis, which makes direct comparisons difficult. Paulus ${ }^{16}$ and Boers and Ramsden ${ }^{17}$ concluded that the evidence presently available does not support the general use of combination treatment. More well designed, controlled clinical trials are needed to determine which, if any, combinations of drugs are most beneficial. More studies are being carried out, ${ }^{18-20}$ and hopefully more knowledge about the mechanisms and biological effects of disease modifying antirheumatic drugs might be helpful in selecting combination treatments where an additive or even synergistic effect is seen. 
1 Ropes M W, Bennett G A, Cobb S, Jacox R, Jessar R A. Revision of diagnostic criteria for rheumatoid arthritis. Bull Rheum Dis 1958; 9: 175-6.

2 Steinbrocker O, Traeger C H, Batterman R C. Therapeutic criteria in rheumatoid arthritis. $\mathcal{F} A M A$ 1949; 140: 659-62.

3 Ingeman-Nielsen $M$, Halskov $O$, Hansen $T M$, Halberg $P$, Stage P, Lorenzen I. Clinical synovitis and radiological lesions in rheumatoid arthritis. Scand $\mathcal{F}$ Rheumatol 1983; 12: $237-40$.

4 Bradley J V. Distribution-free statistical tests. Englewood Cliffs: Prentice Hall, 1968.

5 McKenna F, Hopkins R, Hinchcliffe K P, Bird H A, Wright $\mathrm{V}$. Gold and penicillamine, alone and in combination in active rheumatoid arthritis [abstract]. 16th International Congress of Rheumatology; May 1985; Sydney, Australia.

6 Scott D L, Dawes P T, Tunn E, et al. Combination therapy with gold and hydroxychloroquine in rheumatoid arthritis: a prospective, randomized, placebo-controlled arthritis: a prospective, randomized, p
study. Br $\mathcal{F}$ Rheumatol $1989 ; 28$ : 128-33.

7 Bunch T W, O'Duffy J D, Tompkins R B, O'Fallon W M. Controlled trial of hydroxychloroquine and D-penicillamine singly and in combination in the treatment of rheumatoid arthritis. Arthritis Rheum 1984; 27: $267-76$.

8 Gibson T, Emery P, Armstrong R D, Crisp A J, Panayi G $\mathrm{S}$. Combined D-penicillamine and chloroquine treatment
of rheumatoid arthritis-a comparative study. $\mathrm{Br} \mathcal{F}$ Rheumatol 1987; 26: 279-84.

9 Williams H J, Ward J R, Reading J C, et al. Comparison of auranofin, methotrexate, and the combination of both in the treatment of rheumatoid arthritis. Arthritis Rheum 1992; 35: 259-69.

10 McCarty D J, Carrera G F. Intractable rheumatoid arthritis. Treatment with combined cyclophosphamide, azathioprine and hydroxychloroquine. $\mathscr{f} A M A \quad 1982 ; 248$ 1718-23.
11 Csuka M E, Carrera G F, McCarty D J. Intractable pheumatoid arthritis. Treatment with combined cyclophosphamide, azathioprine and hydroxych

12 Taggart A J, Hill J, Astbury C, Dixon J S, Bird H A, Wright V. Sulphasalazine alone or in combination with D-penicillamine in rheumatoid arthritis. $B r \mathcal{F}$ Rheumatol 1987; 26: 32-6

13 Sievers K, Hurri L. Combined therapy of rheumatoid arthritis with gold and chloroquine. Acta Rheumatol Scand 1963; 9: 48-55.

14 Biro J A, Segal A M, McKenzie A H, Mazenec D J, Wilke W S. The combination of methotrexate and azathioprine for resistant rheumatoid arthritis [abstract]. Arthritis Rheum 1987; 30 (suppl 4): 18.

15 Bentzon M W, Gad I, Halberg P, et al. Influence of previous gold treatment and other patients variables on outcome of treatment with disease modifying anti-rheumatic drugs (DMARD) in patients with rheumatoid arthritis. Clin Rheumatol 1986; 5: 39-48.

16 Paulus $\mathrm{HE}$. The use of a combination of disease-modifying antirheumatic agents in rheumatoid arthritis. Arthritis Rheum 1990; 33: 113-20.

17 Boers $M$, Ramsden $M$. Longacting drug combinations in rheumatoid arthritis: a formal overview. $\mathcal{f}$ Rheumatol 1991; 18: 316-24.

18 Kantor S M, Wallin B A, Grier C E, McCafferty J P, Wetherington J D, Fox M J. Combination of auranofin and methotrexate as initial DMARD therapy in RA [abstract]. 12th European Congress of Rheumatology; July 1991; Budapest, Hungary.

19 Schleusser B, Herborn G, Rau R. Methotrexate compared with methotrexate and gold in rheumatoid arthritis [abstract]. 12th European Congress of Rheumatology; July 1991; Budapest, Hungary.

20 Luthra H S. Double-blind study comparing auranofin and hydroxychloroquine alone or in combination in rheumatoid arthritis [abstract]. 12th European Congress of Rheumatology; July 1991; Budapest, Hungary. 